\title{
Pseudoaneurysm of the femoral artery after cardiac catheterisation: diagnosis and treatment by manual compression guided by Doppler colour flow imaging
}

\author{
P Currie, C M Turnbull, T R D Shaw
}

\begin{abstract}
Objective-To assess the value of Doppler colour flow imaging for diagnosing and guiding non-surgical treatment of pseudoaneurysm of the femoral artery complicating cardiac catheterisation. Design-A prospective study.

Setting-Cardiac department in a teaching hospital.

Patients-9 patients (8 female, 1 male) who presented with pseudoaneurysm 1-15 days after cardiac catheterisation.

Interventions-The femoral arterial communication to the false aneurysm was localised by Doppler colour flow imaging. Manual pressure was then applied to the ultrasound transducer which was positioned directly over the site of the arterial communication. Pressure was progressively increased until it was sufficient to prevent colour flow from the artery into the false aneurysm cavity while allowing Doppler flow to continue within the arterial lumen.
\end{abstract}

Main outcome measures-Characteristics of pseudoaneurysm, duration of manual compression, success rate, follow up.

Results-The pseudoaneurysms ranged from 1.3 to $5.5 \mathrm{~cm}$ in length. Six pseudoaneurysms were $1 \cdot 3-2 \cdot 0 \mathrm{~cm}$ away from the arterial puncture. The pseudoaneurysm was closed in $8 / 9$ patients by compression exerted manually through the transducer for $25-40$ minutes ( 3 successful cases required two or three periods of compression within 48 hours). No pseudoaneurysm recurred during 14-61 days of follow up.

Conclusions-Most pseudoaneurysms of the femoral artery can be treated by a period of manual pressure applied with an ultrasound transducer and guided by Doppler colour flow.

(Br Heart f 1994;72:80-84)

At cardiac catheterisation a false aneurysm can develop at the femoral artery puncture site approximately once in every 300 procedures. ${ }^{1}$ Such aneurysms are four times more common after coronary balloon angioplasty and eleven times more common after more complex interventions such as coronary stenting or directional atherectomy. ${ }^{1}$ The incidence of this complication is increased further after thrombolytic therapy. ${ }^{2}$ Over $60 \%$ of such false aneurysms need surgical repair. ${ }^{1}$ Bredlau et al found that one in 140 patients undergoing elective coronary angioplasty needed an operation for this complication. ${ }^{3}$ Non-surgical treatment of post-catheterisation false aneurysms could reduce patient morbidity, shorten hospital stay, and reduce the demand on vascular surgical resources.

False aneurysms of the femoral artery after angiography can be reliably diagnosed by Doppler colour flow imaging. ${ }^{4}$ Recent reports suggested that they may be successfully closed by a period of compression directly over the site of the arterial communication to the aneurysm. ${ }^{5-7}$ We describe our experience of using ultrasound imaging for the diagnosis and treatment of pseudoaneurysms of the femoral artery in nine patients.

\section{Patients and methods} PATIENTS

In a 13 month period during which there were 1540 cardiac catheterisations at the Western General Hospital, 12 patients with painful swollen haematomas in the groin after cardiac catheterisation were scanned. In four $(0.3 \%)$ there was a haematoma but no pseudoaneurysm. The other eight $(0.5 \%)$ each had a false aneurysm. Another patient (case 6) in whom a pseudoaneurysm of the femoral artery developed after cardiac catheterisation at another hospital is also reported in this series.

Of the nine patients with pseudoaneurysm (table 1) eight were women and six of them were slim. The women were $43-76$ years old and had undergone cardiac catheterisation via a 6 or $7 \mathrm{~F}$ sheath in the right femoral artery. Patient number 7 was a 66 year old man in whom a pseudoaneurysm developed 2 weeks after coronary balloon angioplasty and stent implantation (via an $8 \mathrm{~F}$ femoral sheath). The systolic blood pressure in four of the patients was $>170 \mathrm{~mm} \mathrm{Hg}$ at the time of catheterisation while the pulse pressure in seven patients was $\geqslant 70 \mathrm{~mm} \mathrm{Hg}$ (table 1 ).

Eight patients were taking aspirin and four patients were taking warfarin (stopped 2 days 
Table 1 Clinical details of patients

\begin{tabular}{|c|c|c|c|c|c|c|c|c|c|}
\hline $\begin{array}{l}\text { Case } \\
\text { No }\end{array}$ & Age & Sex & Diagnosis & $\begin{array}{l}B P \\
(m m H g)\end{array}$ & $\begin{array}{l}\text { Gauge of } \\
\text { femoral } \\
\text { arterial } \\
\text { sheat }\end{array}$ & $\begin{array}{l}\text { Sheath } \\
\text { in } \\
\text { femoral } \\
\text { vein }\end{array}$ & $\begin{array}{l}\text { Drug } \\
\text { treatment }\end{array}$ & $\begin{array}{l}\text { Body } \\
\text { Weight } \\
\text { (kg) }\end{array}$ & $\begin{array}{l}\text { Body mass } \\
\text { index } \\
\left(\text { kg } \text { m }^{-2}\right)\end{array}$ \\
\hline $\begin{array}{l}1 \\
2 \\
3 \\
4 \\
5 \\
6 \\
7 \\
8 \\
9\end{array}$ & $\begin{array}{l}65 \\
76 \\
72 \\
66 \\
43 \\
58 \\
66 \\
68 \\
61\end{array}$ & $\begin{array}{l}F \\
F \\
F \\
F \\
F \\
F \\
M \\
F \\
F\end{array}$ & $\begin{array}{l}\text { IHD } \\
\text { MVD } \\
\text { MVD/IHD } \\
\text { IHD } \\
\text { IHD } \\
\text { Non-cardiac } \\
\text { IHD } \\
\text { Non-cardiac } \\
\text { IHD }\end{array}$ & $\begin{array}{l}180 / 80 \\
120 / 70 \\
180 / 100 \\
175 / 80 \\
175 / 100 \\
110 / 70 \\
130 / 55 \\
155 / 85 \\
160 / 54\end{array}$ & $\begin{array}{l}\text { F6 } \\
\text { F6 } \\
\text { F6 } \\
\text { F6 } \\
\text { F6 } \\
\text { F7 } \\
\text { F8 } \\
\text { F6 } \\
\text { F6 }\end{array}$ & $\begin{array}{l}\text { No } \\
\text { Yes } \\
\text { Yes } \\
\text { No } \\
\text { No } \\
\text { No } \\
\text { No } \\
\text { No } \\
\text { No }\end{array}$ & $\begin{array}{l}\text { Aspirin } \\
\text { Warfarin } \\
\text { Warfarin/aspirin } \\
\text { Aspirin } \\
\text { Aspirin } \\
\text { Aspirin } \\
\text { Warfarint/aspirin } \\
\text { Warfarint/aspirin } \\
\text { Aspirin }\end{array}$ & $\begin{array}{l}65 \\
51 \\
57 \\
57 \\
84 \\
50 \\
73 \\
78 \\
76\end{array}$ & $\begin{array}{l}25 \\
19 \\
23 \\
25 \\
25 \\
20 \\
29 \\
30 \\
32\end{array}$ \\
\hline
\end{tabular}

IHD, ischaemic heart disease; MVD, mitral valve disease; * Patient referred for treatment from another hospital; tprothrombin time ratio $>2.5$ when pseudoaneurysm treated.

before the catheterisation in three cases). Two patients (numbers 7 and 8 ) had a prothrombin time ratio $>2.5$ on the day that their pseudoaneurysm was treated. A F8 sheath was placed in the ipsilateral femoral vein in two patients-including case 2 who underwent balloon dilatation of the mitral valve and received heparin (100 units $/ \mathrm{kg}$ ) intravenously after transseptal puncture.

\section{CLINICAL PRESENTATION}

Seven patients had needed prolonged manual compression (that is, at least 20 minutes) to stop bleeding after the femoral sheath was removed. All patients had become aware of a painful haematoma in the groin within 48 hours of cardiac catheterisation. A localised region of pulsation was apparent within the haematoma in six of them but in three a pseudoaneurysm was initially considered unlikely on clinical examination. Two patients were first treated by bed-rest (for 2 and 4 days) before an ultrasound scan was performed.
DIAGNOSIS OF PSEUDOANEURYSM OF THE FEMORAL ARTERY

We performed ultrasound scans of the femoral puncture site in any patient in whom a significant groin swelling developed after catheterisation, using an Advanced Technology Systems Ultramark 9 Ultrasound System with a $2 \cdot 25 \mathrm{MHz}$ phased array transducer. The depth was usually adjusted to the minimum of the range $(4.0 \mathrm{~cm})$. The transducer was placed over the femoral puncture site so that the femoral artery was imaged in the longitudinal plane. Gain was reduced until the arterial lumen was free of echos. The colour Doppler gain was then adjusted until the pulsatile flow in the arterial lumen could be seen but the surrounding subcutaneous tissue remained virtually free of colour. It was possible to visualise clearly the common femoral artery and its bifurcation into its superficial femoral and profunda femoris branches.

All regions of swelling, firmness, or pulsation surrounding the puncture site were sys-
Figure 1 Ultrasound scan showing a pseudoaneurysm (PA) arising from the common femoral artery (FA). The echo-free aneurysm cavity is surrounded by a region of uniformly echogenic thrombus $A$ colour thrombus. A colour
Doppler scan identifies the arterial lumen, the defect in the arterial wall (green), and systolic blood flow into the pseudoaneurysm cavity (red).

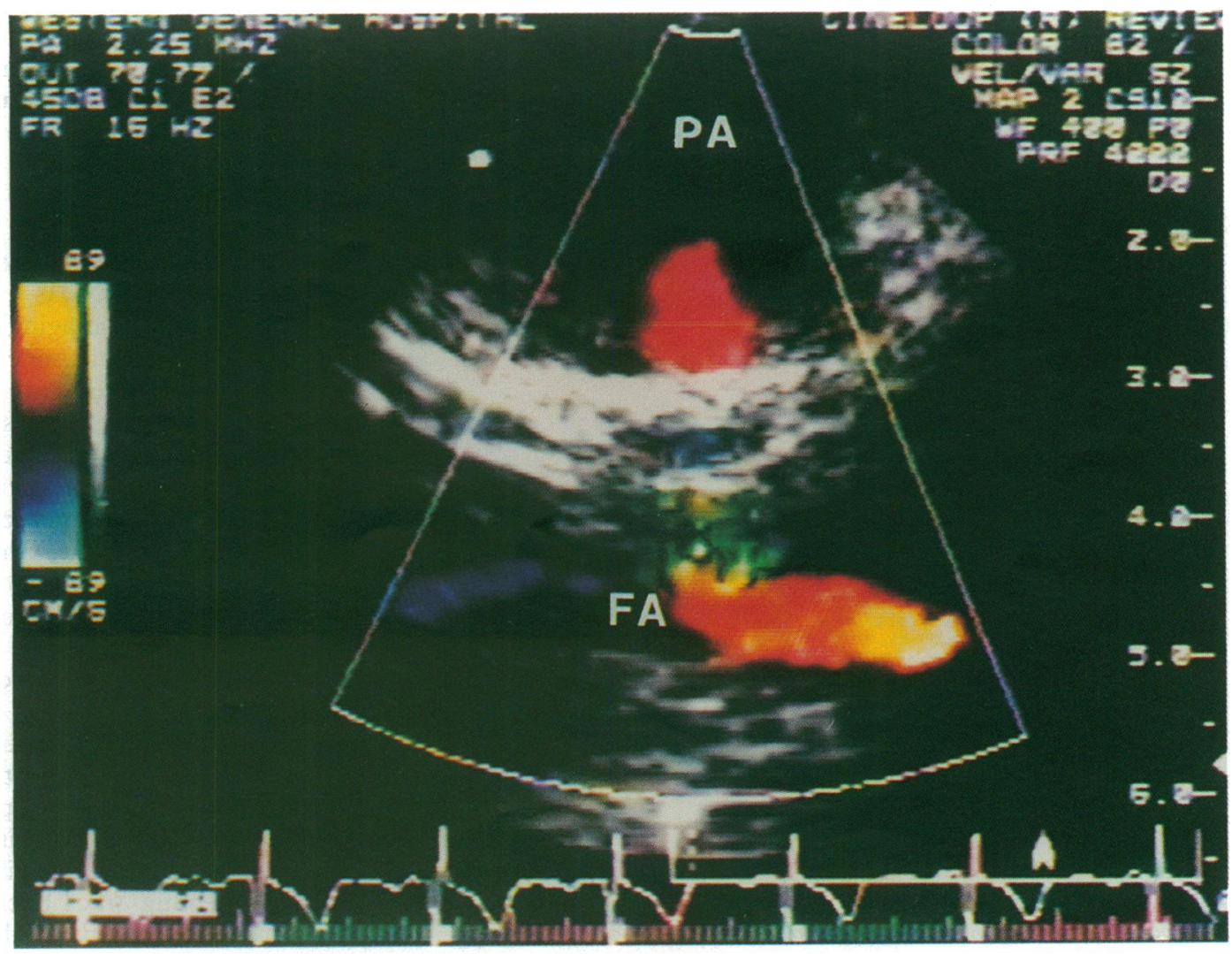




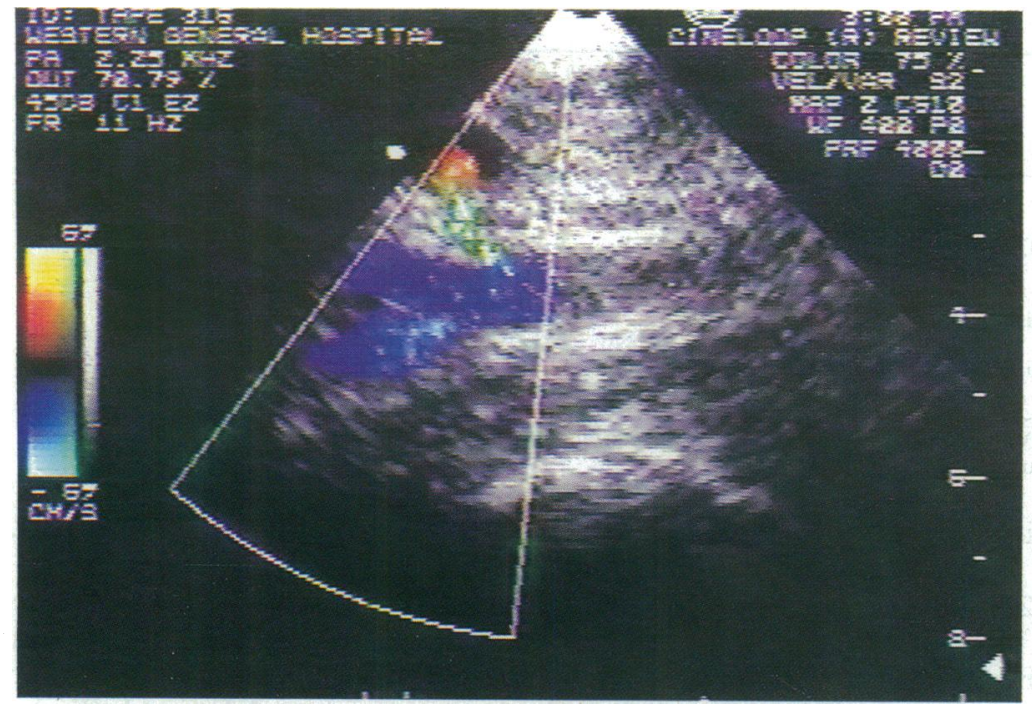

Figure 2 Colour Doppler scan showing a pseudoaneurysm cavity communicating with a defect in the common femoral artery just proximal to its bifurcation.

tematically imaged by sliding the transducer along multiple planes parallel to the femoral artery. A haematoma was seen as a uniform echogenic region. A pseudoaneurysm appeared as a superficial echo-free space that was usually roughly spherical and expanded with each systolic arterial pulsation: with colour Doppler a red pulsatile signal (or green in the presence of turbulence) was detected within the cavity of the false aneurysm moving towards the transducer (figs 1 and 2). When this pulsatile signal was scanned by pulsed or continous wave Doppler a to-and-fro wave form was detected (fig 3), as described by Abu-Yousef et al. ${ }^{8}$

With colour Doppler, it was possible to identify the leaking puncture site in the femoral artery and to follow the communicating channel between the arterial lumen and the pseudoaneurysm cavity (figs 1 and 2).

METHOD FOR CLOSING FALSE ANEURYSMS The groin was cleaned with povidone-iodine

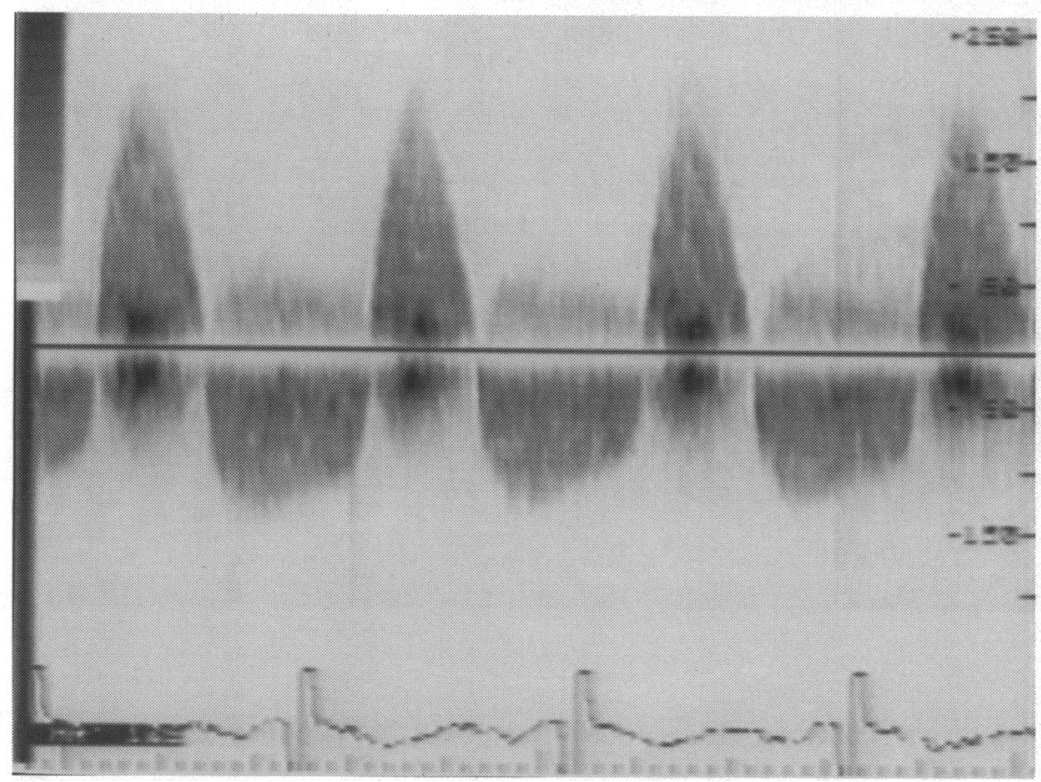

Figure 3 A continuous wave Doppler recording from the anterior aspect of a pseudoaneurysm of the common femoral artery showing the typical "to-and-fro" signal. 8
MSP $10 \%$ solution (Betadine) and at least 20 $\mathrm{ml}$ of $2 \%$ lignocaine solution was infiltrated in the subcutaneous tissue surrounding the false aneurysm. Five patients were given additional analgesia: two intravenous morphine (5 mg), one sublingual buprenorphine $(0.2 \mathrm{mg})$, and two oral paracetamol $(1 \mathrm{~g})$.

Using colour flow Doppler for guidance we positioned the ultrasound transducer precisely over the defect in the wall of the femoral artery (fig 4). We exerted sufficient manual pressure on the transducer probe, which was directly over the artery, until Doppler colour flow from the artery into the false aneurysm cavity ceased and colour flow pulsations along the arterial lumen continued. Constant manual pressure was maintained for about 25 minutes; then the pressure was gradually released while the false aneurysm cavity and the defect in the artery were carefully scanned for a Doppler colour flow signal (that is, a persistent leak). If the pseudoaneurysm had not closed then manual pressure was applied for a further 5-10 minutes before the pressure was gradually released again and the region was scanned for a persistent colour flow signal. If required, the procedure was continued for up to 50 minutes but prolonged manual compression was limited by the fatigue of the investigator or the patient or both. If the procedure failed a second attempt was made within 24 hours.

In one patient (case 6) we used a FemoStop inflatable mechanical device (Radi Medical Systems, UK to compress the pseudoaneurysm for 60 minutes. This second attempt at compression was unsuccessful. In two patients the FemoStop was applied for 1-4 hours to prevent a recurrence after initial closure of the pseudoaneurysm by manual compression.

If the aneurysm was closed the patient was kept on bed rest until the next day, when an ultrasound scan was repeated. If there was no recurrence of the pseudoaneurysm the patient was discharged home.

\section{Results}

ULTRASOUND APPEARANCE OF PSEUDOANEURYSMS

Ultrasound imaging showed six spherical (1.3-3.5 cm diameter) and three large ovoid (about $2.5 \times 5.0 \mathrm{~cm}$ ) pseudoaneurysms (table 2 ). One patient (case 4) needed prolonged scanning of the haematoma to locate the pseudoaneurysm cavity. Only three pseudoaneurysms were directly anterior to the arterial puncture site whereas the other lesions were lateral or distal to it (table 2).

In all patients colour Doppler identified a channel connecting the cavity of the false aneurysm to the arterial puncture site. The puncture site was in the anterior wall of the common femoral artery in seven cases. In one case the lateral aspect of the common femoral artery had been punctured-the arterial puncture site in this patient (case 4) was located with some difficulty by following the connecting tract back to the arterial lumen from the cavity of the false aneurysm. The 
A

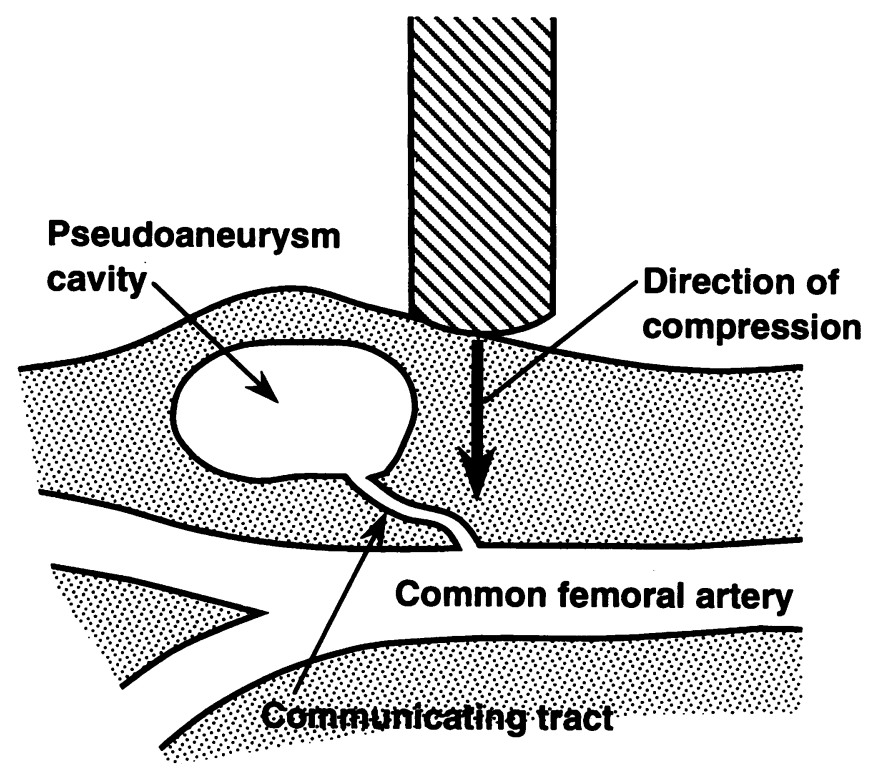

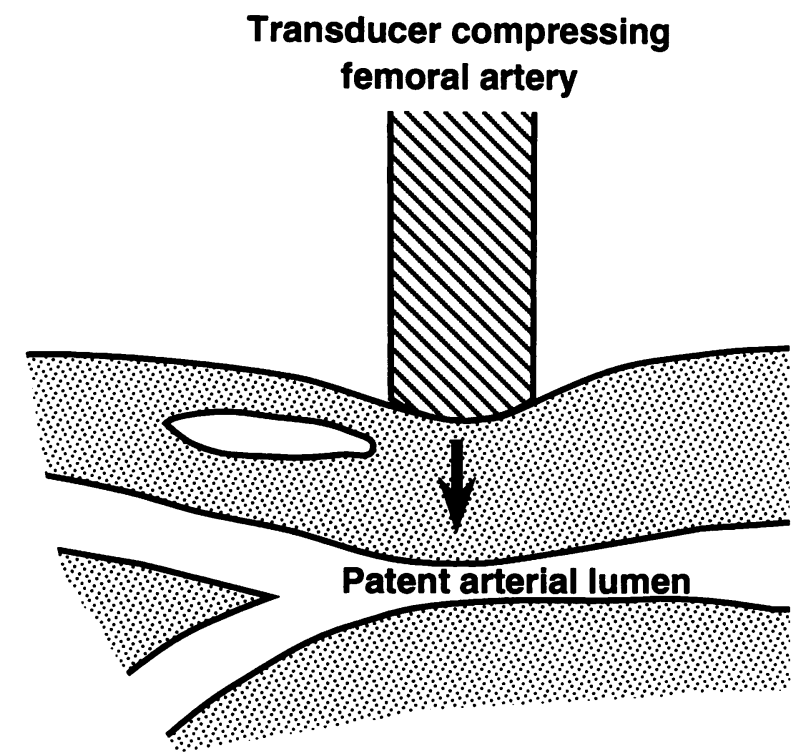

Figure 4 Technique for non-surgical closure of pseudoaneurysm of the femoral artery. (A) The transducer is positioned directly over the defect in the femoral artery (which may be displaced from the aneurysm cavity). (B) The artery is compressed so that flow into the cavity ceases while flow within the arterial lumen is maintained.

Table 2 Characteristics of pseudoaneurysms and outcome of non-surgical closure

\begin{tabular}{|c|c|c|c|c|c|c|c|c|}
\hline $\begin{array}{l}\text { Case } \\
\text { No }\end{array}$ & $\begin{array}{l}\text { Shape of } \\
P A\end{array}$ & $\begin{array}{l}\text { Size } \\
\text { of } P A \\
\text { (cm) }\end{array}$ & $\begin{array}{l}\text { Relation of } \\
P A \text { to puncture } \\
\text { in artery }\end{array}$ & $\begin{array}{l}\text { Site of } \\
\text { puncture } \\
\text { in arteryt }\end{array}$ & $\begin{array}{l}\text { Timing of } \\
\text { treatment } \\
\text { (days) } \ddagger\end{array}$ & $\begin{array}{l}\text { Duration of } \\
\text { compression } \\
\text { (min) }\end{array}$ & Success & $\begin{array}{l}\text { Follow up } \\
\text { (days) }\end{array}$ \\
\hline $\begin{array}{l}1 \\
2 \\
3 \\
4 \\
5 \\
6 \\
7 \\
8 \\
9\end{array}$ & $\begin{array}{l}\text { Spherical } \\
\text { Spherical } \\
\text { Spherical } \\
\text { Spherical } \\
\text { Ovoid } \\
\text { Ovoid } \\
\text { Spherical } \\
\text { Ovoid } \\
\text { Spherical }\end{array}$ & $\begin{array}{l}1.8 \\
2.3 \\
1.3 \\
2.2 \\
4.3 \times 2.3 \\
4.0 \times 2.2 \\
1.5 \\
5.5 \times 3.0 \\
3.5\end{array}$ & $\begin{array}{l}\text { Anterior } \\
1.3 \mathrm{~cm} \text { distal } \\
2.0 \mathrm{~cm} \text { lateral } \\
2.0 \mathrm{~cm} \text { lateral } \\
\text { Anterior } \\
2.0 \mathrm{~cm} \text { distal } \\
\text { Anterior } \\
1.5 \mathrm{~cm} \text { distal } \\
1.5 \mathrm{~cm} \text { distal }\end{array}$ & $\begin{array}{l}\text { Anterior } \\
\text { Anterior } \\
\text { Anterior } \\
\text { Lateral } \\
\text { Anterior } \\
\text { Anterior } \\
\text { Anterior } \\
\text { Medial } \\
\text { Anterior }\end{array}$ & $\begin{array}{l}4 \\
4 \\
1 \\
1 \\
1 \\
2 \\
15 \\
1 \\
1\end{array}$ & $\begin{array}{l}35 \\
25 \\
30 \text { and } 40 \$ \\
25 \text { and } 35 \$ \\
30 \\
50 \text { and } 609 \\
30 \\
30,35,30 \$ \pi \\
30 \$\end{array}$ & $\begin{array}{l}\text { Yes } \\
\text { Yes } \\
\text { Yes } \\
\text { Yes } \\
\text { Yes } \\
\text { No } \\
\text { Yes } \\
\text { Yes } \\
\text { Yes }\end{array}$ & $\begin{array}{l}49 \\
14 \\
26 \\
61 \\
41 \\
S \\
55 \\
34 \\
20\end{array}$ \\
\hline
\end{tabular}

PA, pseudoaneurysm. *Measurement relative to midpoint of pseudoaneurysm cavity; fall punctures were in the common femoral artery; frelative to cardiac catheterisation; אclosed only by further periods of manual compression; ftreatment assisted by mechanical compression using the FemoStop device; S, patient treated by vascular surgery.

arterial puncture was in the medial wall of the common femoral artery in patient 8 .

NON-SURGICAL CLOSURE OF PSEUDOANEURYSMS

Non-surgical closure of a pseudoaneurysm was attempted on the day after catheterisation in five patients and on days $2,4,4$, or 15 in the other four. Doppler guided manual compression applied with the transducer to the arterial puncture sites for initial periods of 25-50 minutes (table 2) closed five of the lesions. In three patients (in which initial compression was unsuccessful) manual compression was applied (successfully) for a further period of 35-40 minutes within 24 hours of the first attempt: patient 8 had a third period of manual compression because the pseudoaneurysm recurred the next day. Initially we failed to close these three false aneurysms because it was difficult to maintain sufficient continuous pressure at the correct point-especially in patients 4 and 8 in whom the lateral or medial aspect of the femoral artery was punctured. Each time a false aneurysm had sealed there was no recurrence of pain at the site.

In four patients a cavity was still apparent after the arterial puncture site had sealed but this was non-pulsatile and there was no evidence of colour flow within it. In the other four patients thrombosis of the pseudoaneurysm cavity was seen after closure of the arterial puncture. No pseudoaneurysm recurred during follow up for 14-61 days (table 2) and two patients (1 and 4) subsequently underwent coronary angioplasty through the site of the previous pseudoaneurysm without difficulty.

Non-surgical closure of the pseudoaneurysm in patient 6 (treated at another hospital) was unsuccessful: the first period of 50 minutes manual compression failed to seal the pseudoaneurysm-mainly because a large surrounding haematoma made it difficult to maintain constant accurate positioning of the compression. Despite a second period of mechanical compression (with a FemoStop device) for 60 minutes on the next day the pseudoaneurysm still did not close: when the FemoStop was in position we could not obtain a clear ultrasound image of the artery to ensure that the leakage of blood from the artery was under control. In patient 6 the femoral artery was surgically repaired. 


\section{Discussion}

We found that ultrasound imaging with colour flow Doppler was a valuable technique for determining the nature of swellings in the groin after cardiac catheterisation. In some patients the precise diagnosis cannot be made from clinical examination alone. It is possible that some pseudoaneurysms are wrongly diagnosed as haematomas when ultrasound is not used. It is also possible that some false aneurysms close spontaneously. Usually colour flow Doppler showed flow into the aneurysm cavity and it was easy to distinguish between a pseudoaneurysm and a haematoma. However, our fourth patient showed that prolonged and careful scanning may be necessary to ensure that a pseudoaneurysm is not overlooked.

Eight of the patients treated were female: others found a higher incidence of pseudoaneurysms in women. ${ }^{3}$ Hypertension may also predispose to pseudoaneurysm: four patients had a systolic blood pressure $>170$ $\mathrm{mm} \mathrm{Hg}$ and seven had a pulse pressure of $\geqslant 70 \mathrm{~mm} \mathrm{Hg}$. Although femoral artery complications are often considered to be commoner in obese patients only three of our patients had a body mass index $>25 \mathrm{~kg} \mathrm{~m}^{-2}$. It has been suggested that false aneurysms are more likely to occur if the superficial femoral artery has been punctured ${ }^{9}$; this did not occur in our patients-all nine were associated with puncture of the common femoral artery.

The fact that compression was successful in eight of nine patients suggests that it is worth attempting to close all false femoral artery aneurysms using this technique guided by colour flow Doppler. Our series also suggests that a further attempt to close the lesion is indicated if the first attempt fails. Firm pressure on a false aneurysm can be very painful but the procedure was well tolerated when adequate local anaesthesia (and sometimes additional analgesic) was given.

It is not yet clear how often this technique would be successful in a larger series of cases. An F6 femoral sheath had been used in seven of the patients in whom compression was successful, and the false aneurysms were small. We believe that closure by compression should be attempted in any patient with post-catheterisation false aneurysms, and that only those in whom the non-surgical technique is unsuccessful should have surgical repair. This view is supported by recent reports of high success rates for closure of false aneurysms by direct pressure with a Cclamp $\left(100 \%^{5}\right)$ or indirect manual pressure with the ultrasound transducer $\left(73 \%^{6}\right)$.
It is possible that manual pressure over the aneurysm without simultaneous colour Doppler imaging might have been successful in our cases. The use of ultrasound, however, indicated the degree of pressure required to prevent flow into the aneurysm. Even intermitent egress of blood through the puncture site in the artery may prevent sealing. Further, in six cases the aneurysm cavity lay some distance from the the defect in the artery and pressure applied generally to the swelling in the groin without ultrasound guidance would have been suboptimally positioned. In two patients the defect was in the side wall of the artery and it was difficult to apply pressure at the correct position. It was also helpful to be able to observe normal flow along the arterial lumen during the period of pressure, allowing longer compression time without creating peripheral ischaemia.

Before the introduction of this new treatment these patients would have been referred to a vascular surgeon and would have undergone surgical repair with a longer hospital stay and convalescence. Ultrasound guided compression seems to be a useful treatment for closure of false aneurysms of the femoral artery and the importance of this procedure will increase if the growing use of complex techniques of interventional coronary angioplasty increases the frequency of false aneurysms of the femoral artery.

1 Muller DWM, Shamir KJ, Ellis SG, Topol ET. Periphera vascular complications after conventional and complex percutaneous coronary interventional procedures. $A m$ Cardiol 1992;69:63-8.

2 Topol EJ, Califf RM, George BS, et al. A randomised tria of immediate versus delayed elective angioplasty after intravenous tissue plasminogen activator in acute myocardial infarction. N Engl f Med 1987;317:581-8.

3 Bredlau CE, Roubin GS, Leimgruber PP, Douglas JS Jr King SB III, Gruentzig AR. In-hospital morbidity and mortality in patients undergoing elective coronary mortality in patients undergoing elective

4 Sheikh KH, Adams DB, McCann R, Lyerly HK, Sabiston DC, Kisslo J. Utility of Doppler colour flow imaging for identification of femoral arterial complications of caridentification of femoral arterial complications

5 Longabaugh JP, Kisslo J. Acute, non-invasive, ultrasound guided repair of vascular injuries following cardiac guided repair of vascular injuries following cardiac
catheterisation [abstr]. $₹ \mathrm{Am}$ Coll Cardiol 1992;19:103.

6 Rocha-Singh KJ, Schwend RB, Schatz RA, Otis SM Teirstein PS. Non-surgical treatment of femoral artery pseudoaneurysm complicating interventional cardiology procedures [abstr]. F Am Coll Cardiol 1992;19:34.

7 Agrawal SK, Pinheiro L, Roubin GS, et al. Nonsurgical closure of femoral pseudoaneurysms complicating cardiac catheterization and percutaneous translumina coronary angioplasty. $\mathcal{F} \mathrm{Am}$ Coll Cardiol 1992;20:610-5.

8 Abu-Yousef MM, Weise JA, Shamma AR. The 'to-and fro' sign: duplex Doppler evidence of femoral artery pseudoaneurysm. Am $\mathcal{F}$ Roentgenol 1988;150:632-4

9 Rapoport S, Sniderman KW, Morse SS, Proto MH, Ross GR. Pseudoaneurysm: a complication of faulty technique in femoral arterial puncture. Radiology 1985 154:529-30 